\title{
Molecular Dynamics Simulation of Ion Adsorption and Ligand Exchange on Orthoclase Surface
}

Qian Liu1 *, Xuan Zhang1, Binbin Jiang2, Jingfeng Li2, Ting Li2, Xianzhen Shao3, Weibin Cail, Hongyuan Wang1, Yuankun Zhang1

1.School of Chemical and Environmental Engineering, China University of Mining and Technology (Beijing), Beijing 100083, China;

2. State Key Laboratory of Water Resource Protection and Utilization in Coal Mining, Beijing, 100011, China

3. Hekou Oil Production Plant of Shengli Oilfield, Sinopec, Shandong, 257200 China

*Corresponding Author E-mail: liuqian331@163.com

\section{Contains:}

Pages:3

Figures:4

Content: This file contains:

The Snapshots of adsorbed species. 


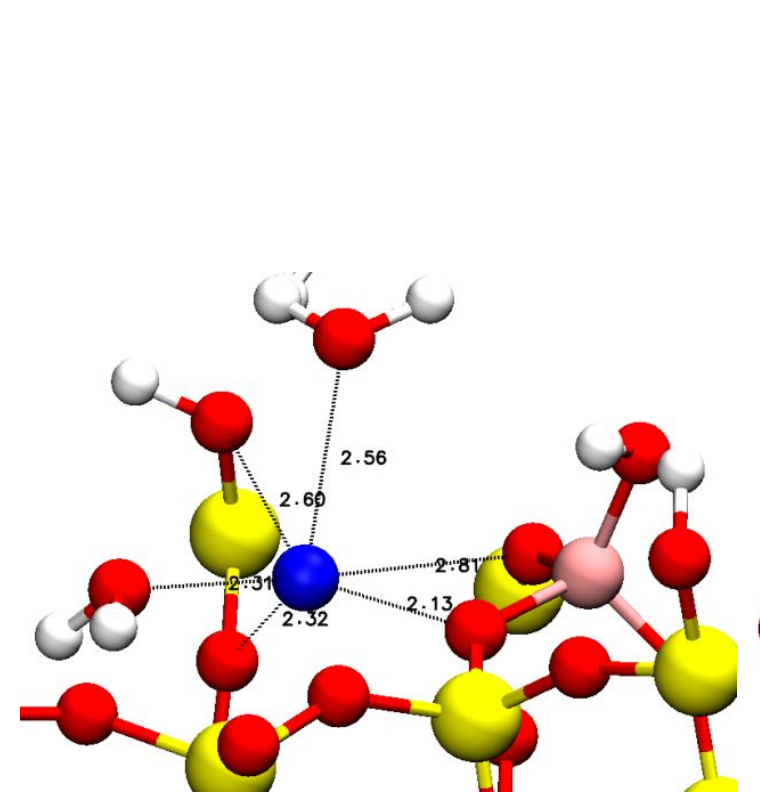

(a)

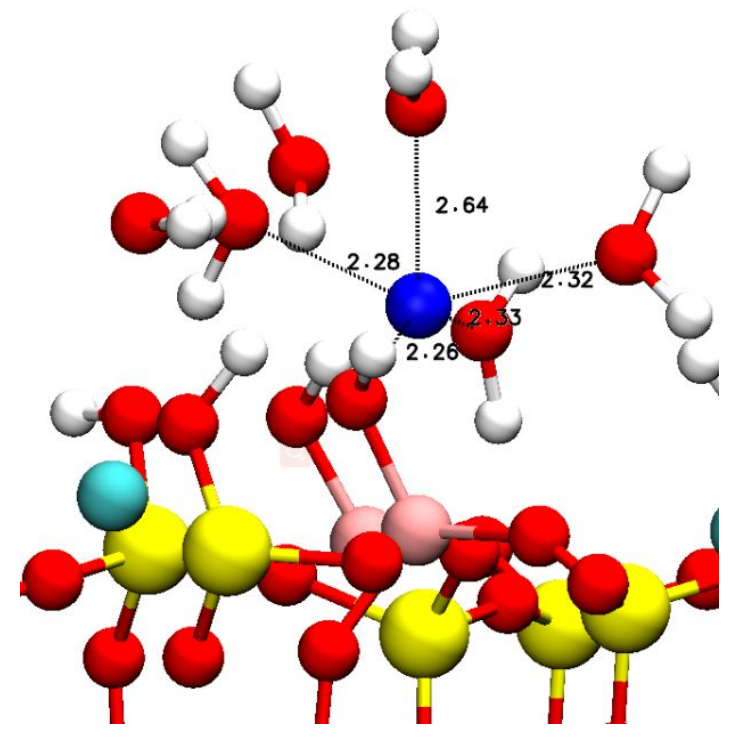

(c)

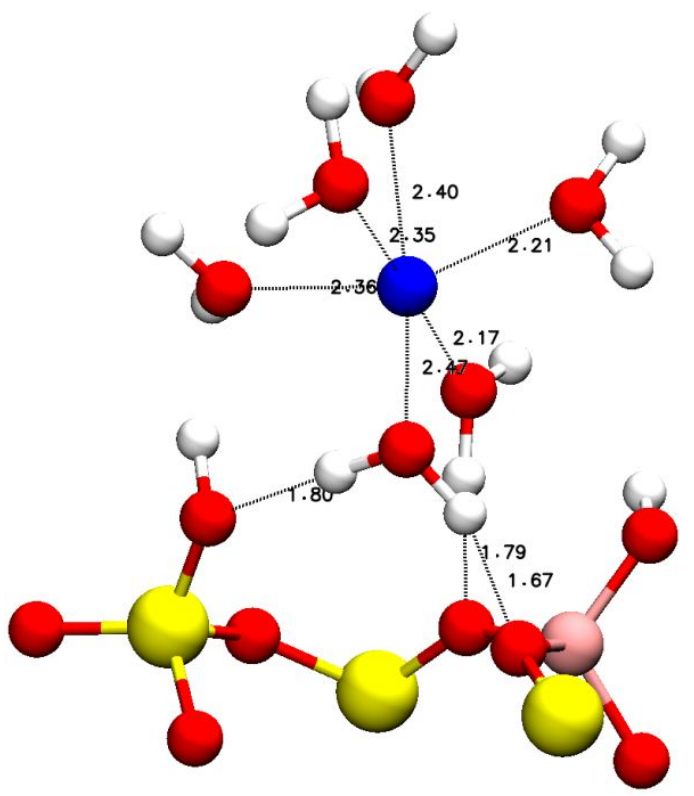

(b)

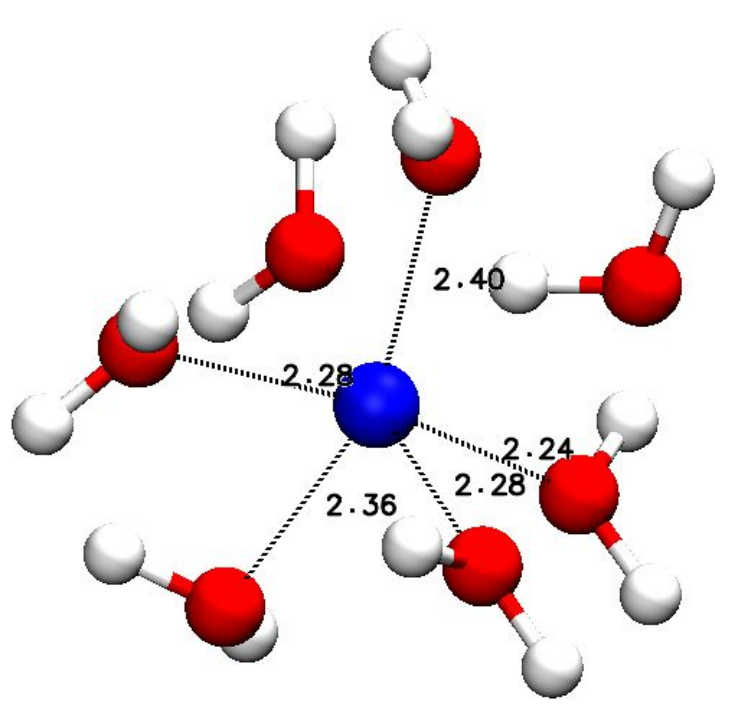

(d)

Figure S1. (a) $\mathrm{Na}^{+}$ion adsorbs in the cavities. (b) $\mathrm{Na}^{+}$ion adsorbs as outer-sphere adsorption. (c) $\mathrm{Na}^{+}$ion is coordinated with aluminol group in the surface. (d) $\mathrm{Na}^{+}$ion is coordinated with $\mathrm{H}_{2} \mathrm{O}$ molecules in the diffuse layer. 


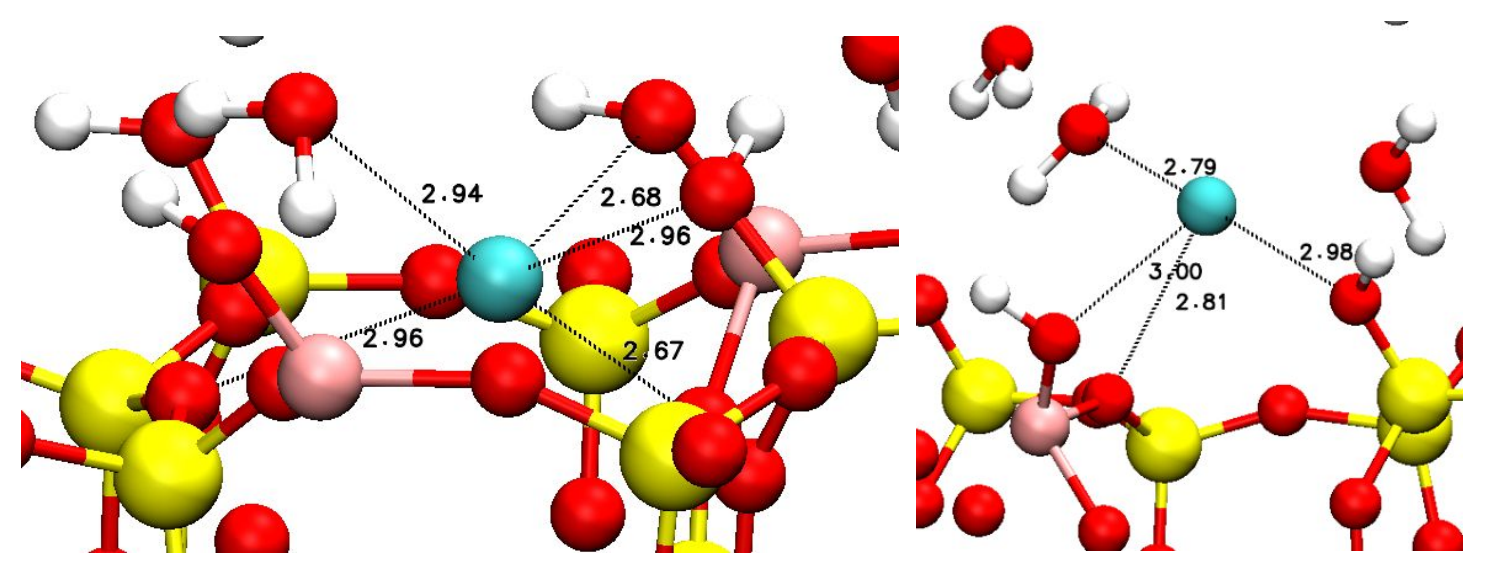

(a)

(b)

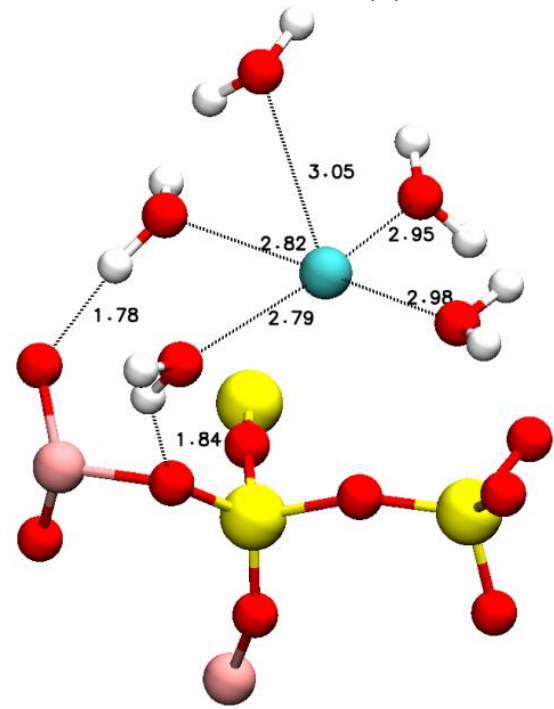

(c)

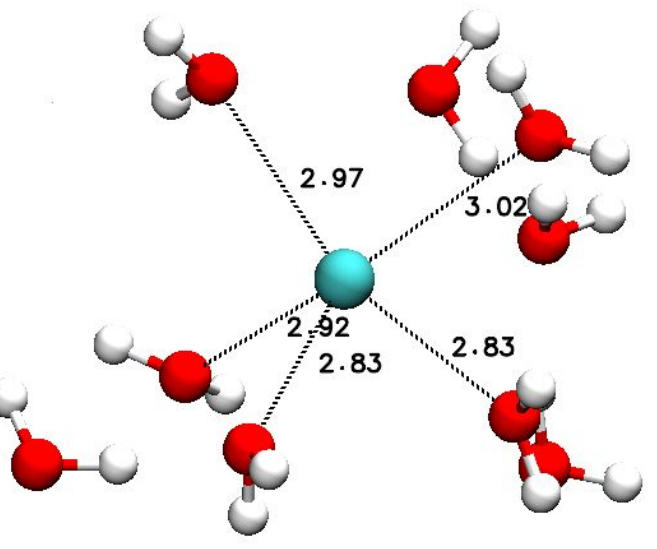

(d)

Figure S2. (a) $\mathrm{K}^{+}$ion adsorbs in the cavities. (b) $\mathrm{K}^{+}$ion is coordinated with aluminol group and silanol group in the surface. (c) $\mathrm{K}^{+}$ion adsorbs as outer-sphere adsorption. (d) $\mathrm{K}^{+}$ion is coordinated with $\mathrm{H}_{2} \mathrm{O}$ in the diffuse layer. 


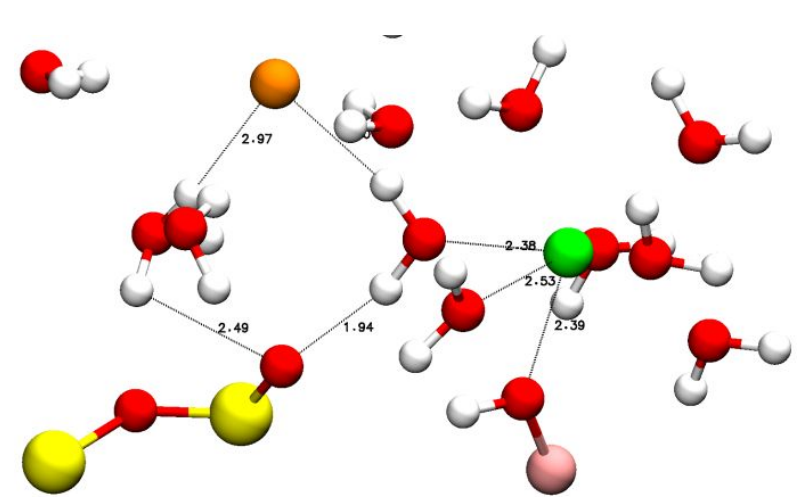

(a)

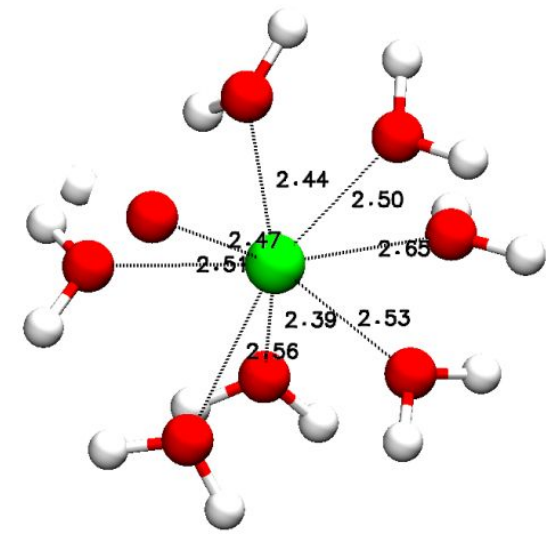

(b)

Figure S3. (a) the co-adsorption of $\mathrm{Ca}^{2+}$ ion and $\mathrm{Cl}^{-}$ion. The $\mathrm{Ca}^{2+}$ is coordinated with aluminol group and the $\mathrm{Cl}^{-}$ion adsorbs as outer-sphere. (b) $\mathrm{Ca}^{2+}$ ion is coordinated with $\mathrm{H}_{2} \mathrm{O}$ in the diffuse layer.

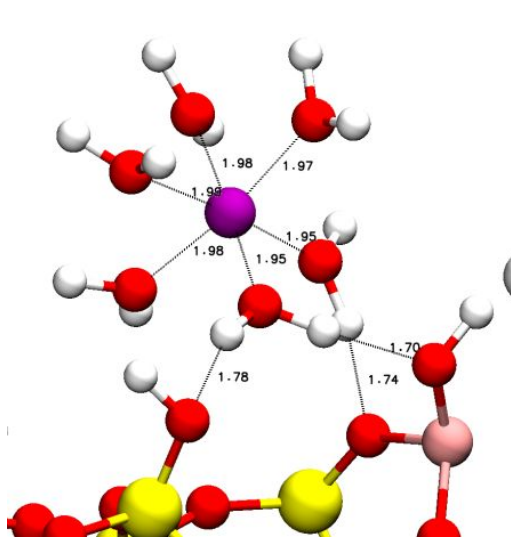

(a)

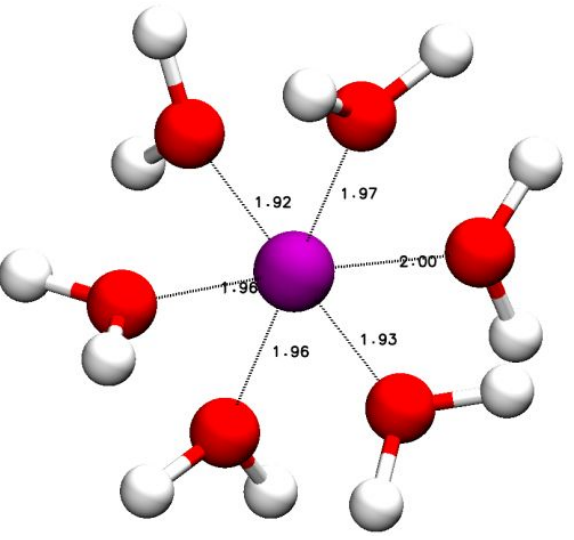

(b)

Figure S4. (a) $\mathrm{Mg}^{2+}$ ion adsorbs as outer-sphere adsorption. (b) $\mathrm{Mg}^{2+}$ ion is coordinated with $\mathrm{H}_{2} \mathrm{O}$ in the diffuse layer. 